\title{
International Travel With a Chronic Medical Illness - Health Risks, Practical Challenges and Evidence-Based Recommendations
}

\author{
Milad Darrat ${ }^{1,2 *}$, Gerard Thomas Flaherty,3® \\ ${ }^{1}$ School of Medicine, National University of Ireland Galway, Galway, Ireland \\ ${ }^{2}$ Department of Endocrinology, Beaumont Hospital, Dublin, Ireland \\ ${ }^{3}$ School of Medicine, International Medical University, Kuala Lumpur, Malaysia
}

Corresponding Author: Milad Darrat, MD, School of Medicine, National University of Ireland Galway, Galway, Ireland. Tel: +353-91495469, Email: m.darrat1@ nuigalway.ie

Received July 24, 2020; Accepted October 12, 2020; Online Published December 12, 2020

\begin{abstract}
Introduction: Primary care practitioners and travel medicine physicians are primarily responsible for identifying individuals who may be unfit for overseas travel and consulting with them pre-travel. Pre-existing medical conditions such as cardiovascular disease, chronic respiratory conditions and diabetes mellitus (DM) have the potential to complicate travel journeys. A considerable percentage of travelassociated illness may be due to the decompensation of a pre-existing medical condition. This review seeks to address the challenges faced by travellers with each of these conditions, including recently updated and evidence-based practical approaches for travel with comorbidities.

Methods: Sources for this review were identified through searches of PubMed/Google Scholar for materials published between 1st January 2000 and 31st December 2019, using combinations of search terms.

Results: The volume of literature on travelling with a pre-existing condition exploded with more than 865 associated articles indexed on the PubMed alone as of March 2020. After screening titles, abstracts and, in some cases, the full text version of indexed articles, 121 articles were deemed relevant to the subject matter of this review.

Conclusion: Rational approaches to pre-planning for travel with a medical condition will contribute to the prevention of problems while in transit as well as when at the travel destination. It is imperative for health care providers to be aware of the preventative measures and current recommendations that should be taken before and during travel to protect individuals with a chronic illness. Further research and studies should be directed to protect this vulnerable group of travellers.

Keywords: International Travel, Pre-Existing Condition, Travel and Chronic Illness, Elderly Traveller
\end{abstract}

Citation: Darrat M, Flaherty GT. International travel with a chronic medical illness - health risks, practical challenges and evidence-based recommendations. Int J Travel Med Glob Health. 2021;9(2): 44-59. doi:10.34172/ijtmgh.2021.09.

\begin{abstract}
Introduction
It is expected that around two billion people will be travelling annually by $2030 .^{1}$ Primary care practitioners and travel medicine physicians are primarily responsible for identifying individuals who may be unfit for overseas travel and consulting with them pre-travel. Some studies report that the majority of travellers with a chronic medical condition would like to receive additional medical advice from their practitioner prior to travel. ${ }^{2-4}$ The average age of travellers is continuing to increase as the population ages. ${ }^{5}$ The complexity of the medical issues involved and the special characteristics of those travelling can be expected to increase as well. An analysis of 89521 ill travellers in the GeoSentinel
\end{abstract}

Network database who sought medical advice after their return showed that older travellers experienced significantly more cases of travel-associated illness overall compared to younger travellers. The leading diagnoses were related to the musculoskeletal $5 \%$, dermatologic $6 \%$, gastrointestinal $6 \%$, respiratory $8 \%$, neurological $9 \%$, and cardiovascular systems $17 \%$ in ascending order of frequency. ${ }^{6}$ A Swiss study reported that $10 \%$ of visits to a travel medicine clinic for a pre-travel consultation were made by travellers over the age of 60 , and $40 \%$ of these travellers had a chronic medical condition. ${ }^{7}$ A recent Irish study showed that $5 \%$ of visitors to a travel medicine clinic were 60 years of age and older, and approximately $80 \%$ had a documented pre-existing medical

Copyright $\odot 2021$ The Author(s). This is an open-access article distributed under the terms of the Creative Commons Attribution License (http:// creativecommons.org/licenses/by/4.0), which permits unrestricted use, distribution, and reproduction in any medium, provided the original work is properly cited. 
condition. ${ }^{8}$

Pre-existing medical conditions, such as cardiovascular disease (CVD), diabetes mellitus (DM) and chronic respiratory conditions, have the potential to complicate international travel. ${ }^{9}$ A considerable percentage of travelassociated illness may be due to the decompensation of pre-existing medical conditions. ${ }^{10}$ Travellers with these medical conditions, including the elderly, young, and pregnant travellers, may present unique problems arising from the special risks of particular diseases, vaccination recommendations, opportunities for drug-drug interactions, physical and mental exhaustion, and whether it is advisable for the traveller to undertake the planned travel at all. ${ }^{10,11}$

It is crucial for travellers with a chronic medical condition to consider factors such as access to medical care, the availability of medical supplies and the effect of weather and dietary changes when planning a trip to a foreign destination. Pre-travel planning is essential for these travellers. ${ }^{12,13}$ Furthermore, a significant factor in promoting safe travel is travelling with a companion who can provide significant assistance as a part of obtaining urgent health care when it is needed. ${ }^{14}$

Travel abroad can be a rewarding and confidence-building pursuit for those limited by a chronic illness. Nonetheless, travellers with pre-existing medical conditions and their health care providers need to consider whether the anticipated benefits of the planned travel experience outweigh the potential health risks associated with a given journey. ${ }^{15,16}$

Regardless of the mode of transportation, it is recommended that travellers with a pre-existing medical condition should attend a pre-travel consultation at least four weeks before departure. ${ }^{17}$ Rational approaches to pre-planning for travel with a medical condition will contribute toward the prevention of problems while in transit as well as at the travel destination. This narrative review article seeks to address the challenges of travellers with chronic medical conditions and it includes recently updated and evidence-based practical guidance for travel with a range of common chronic illnesses.

\section{Methods}

The literature review was completed using the PubMed, Ovid/Medline, and Google Scholar databases. Preference was given to articles published between 1st January 2000 and 31st December 2019. Combinations of the following search terms were employed: pre-existing medical conditions and travel, traveller with a chronic illness/medical condition, each individual condition and travel abroad, air travel and preexisting medical conditions, and elderly travellers. Published articles were used as a source of further reference not yielded by the primary search. The guidelines of the major professional societies and textbooks written by recognised experts in the field of travel medicine were consulted to source information not available elsewhere. Information sources not published in the English language were excluded.

\section{Results}

The volume of literature on travelling with a pre-existing condition exploded with more than 865 associated articles indexed on the PubMed alone as of March 2020. After screening titles, abstracts and, in some cases, the full text version of indexed articles, 121 articles were deemed relevant to the subject matter of this review. The selected sources were agreed upon by the authors (Table 1).

\section{Cardiovascular Diseases}

\section{Coronary Heart Disease}

Acute coronary syndromes (ACS) are one of the commonest causes of death while travelling abroad. ${ }^{18-21}$ They account for a fifth of all in-flight medical emergencies in some reports. ${ }^{22,23}$ Physical and mental stress, weather changes and dehydration represent major precipitating factors. ${ }^{24,25}$ These triggers may induce myocardial ischemia and worsen the health status of travellers with coronary heart disease (CHD) ${ }^{25}$ Therefore, it is critical for health care professionals to educate travellers with known CHD or CVD risk factors on the health risks of travelling abroad, including and assessing their medical fitness and preparedness for travel. Furthermore, they should advise them to carry copies of their medical records which details their diagnosis, current medications, a recent electrocardiogram and their general practitioner's telephone number (Box 1). ${ }^{26,27}$ A reliance on medical history and a physical examination with baseline routine investigations is more appropriate than pre-flight stress testing. ${ }^{28}$ The specific time period for safe air travel for a patient with a recent ACS is not easily identified in the existing literature. It is recommended to observe a waiting period of seven to ten days for an uncomplicated ACS event or in a patient who has undergone a successful revascularization. This is extended to four to six weeks for a complicated ACS event. ${ }^{29-34}$ However, specific time period recommendations are likely best made on an individual basis. ${ }^{35}$ Reports regarding the incidence, type, and management of acute cardiac events on cruise ship travel are sparse in the literature. Nonetheless, a risk assessment and pre-travel planning should follow the general approach for other modes of travel. ${ }^{36}$

\section{Hypertension}

There were around 1.13 billion individuals living with hypertension (HTN) in $2015 .{ }^{37}$ It is estimated that this number will increase by $15 \%-20 \%$ ( 1.5 billion) by $2025 .{ }^{38}$ Despite this, there is a lack of specific data on the prevalence of HTN among international travellers with cross-sectional studies reporting that HTN represents the most common pre-existing medical condition among travellers. ${ }^{4,8,39-41}$ There is insufficient literature to guide the management of this condition during travel abroad. There is a significant variability in the blood pressure responses due to multiple factors during travel that could result in adverse consequences. ${ }^{42}$ Therefore, patients with uncontrolled or labile HTN should minimise their travel to high altitude and hotter locations until their condition has been optimally managed. ${ }^{43}$ Patients should continue to check their blood pressure while travelling and adjust their medication doses if needed. ${ }^{44}$ Diuretics can cause a decrease of $10 \%$ of body plasma volume. The dose may need to be 
Table 1. Relevant Previous Articles on Travel With a Pre-existing Medical Condition

\begin{tabular}{|c|c|c|}
\hline Medical condition & Authors & Quality of the Evidence \\
\hline \multirow{10}{*}{ Cardiovascular disease } & Possick and Barry ${ }^{25,28}$ & Review \\
\hline & Ross and colleagues ${ }^{34}$ & Guideline summary \\
\hline & Novaro and colleagues ${ }^{36}$ & Large cohort study \\
\hline & Smith and colleagues ${ }^{49}$ & Review \\
\hline & Rimoldi and colleagues ${ }^{52}$ & Review \\
\hline & Donegani and colleagues ${ }^{56}$ & Review \\
\hline & Hammadah and colleagues ${ }^{61}$ & Review \\
\hline & Joy ${ }^{63}$ & Review \\
\hline & Simpon and colleagues ${ }^{64}$ & Guideline summary report \\
\hline & Lucas ${ }^{80}$ & Review \\
\hline Hypertension & Luks and colleagues ${ }^{42}$ & Review \\
\hline \multirow{2}{*}{ Heart failure } & Zadi and colleagues ${ }^{55}$ & Review \\
\hline & Beri and colleagues ${ }^{60}$ & Expert opinion \\
\hline \multirow{5}{*}{ Respiratory disease } & Ahmedazi and colleagues ${ }^{85}$ & Guideline summary report \\
\hline & Coker and colleagues ${ }^{87}$ & Cohort study \\
\hline & Ríoa and colleagues ${ }^{99}$ & Guideline summary report \\
\hline & Nichloson and Sznajder ${ }^{104}$ & Review \\
\hline & Chetta and colleagues ${ }^{108}$ & Cohort study \\
\hline \multirow{2}{*}{ Chronic obstructive airways disease } & Ergan and colleagues ${ }^{86}$ & Review \\
\hline & Edvardsen and colleagues ${ }^{88}$ & Cohort study \\
\hline \multirow{4}{*}{ Cystic fibrosis } & Hirche and colleagues ${ }^{106}$ & Guideline summary report \\
\hline & Miller and colleagues ${ }^{107}$ & Cohort study \\
\hline & Webb $^{116}$ & Expert opinion \\
\hline & Verma and colleagues ${ }^{117}$ & Case series \\
\hline \multirow{11}{*}{ Diabetes mellitus } & Mullin and colleagues ${ }^{120}$ & Review \\
\hline & Trikudanathan and Hirsh ${ }^{121}$ & Review \\
\hline & Izadi and colleagues ${ }^{122}$ & Review \\
\hline & Levy-Sharga and colleagues ${ }^{123}$ & Case-control study \\
\hline & Pavela and colleagues ${ }^{127}$ & Systematic review \\
\hline & Chelminska and Jaremie ${ }^{128}$ & Review \\
\hline & Nassar and colleagues ${ }^{130}$ & Review \\
\hline & Itzstein ${ }^{131}$ & Case series \\
\hline & Ghosh and colleagues ${ }^{139}$ & Expert opinion \\
\hline & Jawad and Kalra ${ }^{140}$ & Review \\
\hline & Casey $^{141}$ & Review \\
\hline \multirow{2}{*}{ Neurological disorder } & Sirven and colleagues ${ }^{144}$ & Retrospective study \\
\hline & Giovanetti ${ }^{150}$ & Review \\
\hline \multirow{2}{*}{ Chronic kidney disease } & Corbett and colleagues ${ }^{153}$ & Cohort study \\
\hline & Knotek and Biel ${ }^{157}$ & Expert opinion \\
\hline \multirow{2}{*}{ Mental disorder } & Felkai and Kurimay ${ }^{159 \& 175}$ & Review \\
\hline & Wieshamann and colleagues ${ }^{161}$ & Retrospective study \\
\hline Chronic medication use & Zwar ${ }^{187}$ & Review \\
\hline
\end{tabular}

adjusted or stopped, particularly when travelling to hotter regions or if the traveller develops travellers' diarrhoea. ${ }^{45}$ In cases of severe dehydration, medical advice should be sought immediately as fluid and electrolyte disturbances can precipitate a cardiac emergency. ${ }^{44,45}$

\section{Heart Failure}

Travel arrangements can be complex for heart failure (HF) patients. Specific evidence relating to travel for HF patients is limited and predominantly relies on that used to advise elderly travellers and travellers with CVD in general. ${ }^{46,47}$ Although air travel is still the preferred choice of transportation for long journeys, there is no class of recommendation to support this advice in the recent literature. ${ }^{26,47}$

A British survey designed to elicit the experiences of 1293 HF patients found that $54 \%$ of patients had travelled by air since their HF diagnosis and only $35 \%$ of those patients experienced health problems, mainly at their final destination. 
Box 1. General Recommendations and Approaches for Travellers With Cardiovascular Disease

- Conduct a full pre-travel clinical assessment of fitness to travel.

- Carry multiple and detailed copies of medical record including current diagnosis, past medical history, any allergies, a list of all medication and a copy of their recent ECG and the details of their physician.

- Carry extra quantities of their medication and keep them in two different pieces of luggage.

- $\quad$ Choose a travel insurance policy that covers their pre-existing cardiac condition with emergency evacuation coverage if needed.

- Carry a pacemaker/ICD identification card with a copy of the ECG with and without using a magnet.

- $\quad$ Arrange with airline company in advance for a low salt diet, gate transportation, in-flight medical oxygen, wheelchair, and special seats.

- Allow enough time to arrive at the airport to avoid stress.

- Keep emergency cardiac medications such as nitroglycerin nearby at all times.

- Check and locate local cardiac centres at the travel destination in advance.

- Wear below the knee flight socks for long-haul travel.

- Monitor fluid intake and avoid over/dehydration.

- Apply sun protection, particularly if on medication such as Amiodarone.

Adopted from Lainscak, ${ }^{46}$ Hammadah, ${ }^{61}$ and Lucas $^{80}$

Only $27 \%$ of all patients expressed a wish not to travel by air in the future. In addition, $38 \%$ of all patients consider flying again if there was more leg room on the airplane, if their personal health improved (18\%), if they could find cheaper travel insurance (19\%), if there was less waiting at the airport (11\%), if the walking distance was shorter, and if there were fewer stairs at the airport (7\%). The authors concluded that air travel is safe for well-managed HF patients. ${ }^{48}$

The current evidence suggests that stable HF patients with mild to moderate limitations (NYHA class II) can tolerate attitude and cabin pressure-related hypoxia for up to 7 hours. Patients with severe limitations (NYHA class III and IV) can tolerate up to one hour of cabin pressure altitude. ${ }^{49-52}$ Nonetheless, a pre-travel assessment including symptomlimited exercise, echocardiography, spirometry, Holter-ECG and hypoxic-challenge testing should be considered for HF patients who are hypoxemic at sea level, especially those with coexistent pulmonary disease. ${ }^{49,53-55}$ In-flight supplemental oxygen is recommended for stable $\mathrm{HF}$ patients with chronic sea-level hypoxia whose $\mathrm{PaO}_{2}$ is $\leq 9.4 \mathrm{kPa}(70 \mathrm{~mm} \mathrm{Hg}){ }^{32,49,56,57}$

$\mathrm{HF}$ patients are at a higher risk of developing venous thromboembolism (VTE) during prolonged air travel. ${ }^{25}$ Howell et al reported that a left ventricular ejection fraction of less than $45 \%$ was associated with an increased risk of VTE, with an odds ratio of 2.8 (95\% CI: 1.4-5.7) in a population of Veteran's Administration patients in the United States. ${ }^{58}$ However, this risk is often underestimated in a HF population during travel. Based on the available evidence, it is recommended to follow a risk stratification system for prophylactic measures to prevent VTE in travellers with a cardiac condition. ${ }^{25,59}$

HF patients are also at a higher risk of fluid imbalance (fluid retention or dehydration) during overseas travel, secondary to exertion, climate changes, diarrhoea, and the personal use of diuretics. ${ }^{55,60}$ Travelling to colder climates may cause an increased heart rate and total peripheral resistance with an increase in myocardial oxygen demand, resulting in worsening angina symptoms for patients with ischaemic cardiomyopathy. ${ }^{61,62}$ In contrast, travelling to warmer regions may lead to more insensible fluid loss with a risk of travellers' diarrhoea, resulting in dehydration. ${ }^{28,61}$ Electrolyte disturbances, particularly hypocalcaemia, could occur and may predispose the patients to arrhythmias. ${ }^{55}$ Close monitoring of body weight, fluid loss replacement and stopping or halving the diuretic and ACE inhibitor drug doses is strongly recommended. ${ }^{53,55,61}$ Potassium-lessening diuretics such as acetazolamide, frequently used for the prophylaxis of acute mountain sickness, should be avoided in travellers already using other diuretics. ${ }^{55,61-63}$ For HF patients travelling long distances by car or bus, diuretics may challenge their comfort due to the limited toilet facilities available during travel. Where possible, patients should be advised to take their diuretics upon arriving at their final destination. ${ }^{64}$

\section{Cardiac Dysrhythmias}

Travelling, particularly by air, carries a low risk of significant cardiac disrhythmia. ${ }^{61}$ For example, $25 \%$ of all flight diversions involving one major airline in 2006 were made to accommodate a suspected cardiac emergency. There were only twelve cardiac arrests, eight demonstrating ventricular dysrhythmia of whom four were successfully resuscitated. ${ }^{65}$ Furthermore, evidence on the use of an automated external defibrillator on American flights showed that the survival rate of resuscitation ranged from $27 \%$ to $40 \% .{ }^{66}$ Altituderelated hypoxia, physical stress, dehydration, and electrolyte disturbance can all lead to sympathetic over-activation and an aggravated risk of cardiac disrhythmias. ${ }^{28,49,50,53,61,67-69}$ Altitude-induced dysrhythmias, in particular, have been responsible for a significant number of sudden cardiac deaths, particularly among patients with pre-existing dysrhythmias or underlying cardiac conditions..$^{52,53,70}$ Hypoxic challenge tests (HCTs) such as the hypoxia altitude simulation test may be helpful to obtain more practical information about possible hemodynamic effects and symptoms during planned highaltitude exposure. ${ }^{49,71,72}$

Atrial fibrillation (AF) represents the most common type of chronic dysrhythmia among travellers. ${ }^{73}$ In 2010 , it was estimated that the number of adults with AF worldwide was 33 million, ${ }^{74}$ with one in four middle-aged adults in Europe and the US developing AF by 2030. ${ }^{75-77}$ Travellers with chronic AF should be stable with appropriate rate/rhythm control and anticoagulation before travelling. ${ }^{49,55,60}$

Patients with dysrhythmias that are associated with an underlying heart disease should follow the disease-specific recommendations to minimise the risk of malignant dysrhythmia occurring during travel. Pre-travel planning and 
treatment should be discussed in detail (i.e., increased doses in case of chronic prophylactic treatment, the so-called 'pill in the pocket'). ${ }^{55,78}$ A stress test or Holter monitor before travel should be negative for significant ischaemic changes. ${ }^{26,49,79}$ Travel is contraindicated in patients with uncontrolled ventricular dysrhythmias and the recent implanting of a cardiac device. ${ }^{49,78,79}$

\section{Implanted Cardiac Devices}

There is a lack of evidence suggesting a significant risk for myocardial ischaemia or dysrhythmias during travel, nor has travel itself been directly linked with the malfunction of either ICDs or pacemakers. ${ }^{28,80}$ Nonetheless, there is a potential for device interference to occur. In a case report by Roche et $\mathrm{al},{ }^{81}$ a passenger with a pacemaker fainted on a business class flight from New York to Paris. It was demonstrated that his pacemaker had been inhibited by a $50 \mathrm{~Hz}$ electric interference during his flight which led to a transient period of asystole. The interference resulted from an electrical disturbance arising from his seat. The authors concluded that inappropriate pacemaker inhibition has become rarer due to the use of bipolar rather than with unipolar leads. Health care professionals should have a basic knowledge of pacemakers or ICDs and they should be aware of when and how to use a magnet in this setting. ${ }^{81}$

Travellers with pacemakers or ICDs should undergo a thorough clinical evaluation by their cardiologist before they travel overseas. ${ }^{26}$ Travellers with these units are encouraged to review the recommendations and restrictions by their individual device manufacturer before travelling to see if there are any specific considerations. They should carry their device identification card and a copy of their ECG along with other medical documents (Box 1). ${ }^{26}$ They should also identify local medical centres with cardiac facilities along their planned travel route. Travellers should ask for a pat-down search during airport security clearance to avoid device interference or inhibition created by handheld security wands. ${ }^{26,79}$

There is little published data about left ventricular assistant devices (LVADs) and travel..$^{82}$ Nevertheless, travellers with LVADs and a stable clinical status can safely travel abroad. ${ }^{61}$ LVADs are sensitive to any loss in body fluid, hence the avoidance of caffeinated beverages and maintaining adequate hydration are important considerations during travel..$^{83}$ The international location of reliable local LVAD centres should be included in any pre-travel planning (Box 1). ${ }^{61}$

\section{Respiratory Disorders}

\section{Chronic Obstructive Pulmonary Disease}

The British Thoracic Society guidelines, published in 2002 and updated in 2011, suggest that in-flight oxygen is not required if the patient's resting capillary oxygen saturation $\left(\mathrm{SpO}_{2}\right)$ is $>95 \%$ while breathing room air. If a patient has a resting room air $\mathrm{SpO}_{2}<92 \%$ at sea level, the traveller will require in-flight oxygen. ${ }^{84,85}$ Nevertheless, several studies have demonstrated that resting oxygen saturation is not a very sensitive predictor for in-flight hypoxemia. ${ }^{86-89}$ Thus the full assessment of the severity of the traveller's chronic obstructive pulmonary disease (COPD) and an assessment of their use of pulse oximetry-based 6-minute walk testing is strongly recommended to guide the selection of COPD patients for further testing with an HCT. ${ }^{88,89}$

Travellers with COPD are usually sedentary during flight. They may have a reduced chance of desaturating. However, even modest exercise under hypobaric conditions may lead to a substantial worsening of their status..$^{90} \mathrm{COPD}$ patients usually struggle to increase their minute ventilation in response to hypoxia. ${ }^{91}$ The changes in the perfusion/ ventilation ratio make it even more difficult for them to maintain adequate oxygenation during the flight. ${ }^{91,92}$ Despite this degree of hypoxemia, some studies have shown that patients with COPD who are exposed to a high altitude for several hours are unlikely to develop severe adverse clinical events. A multicentre observational study in the United Kindom assessed the outcomes of commercial air travel in patients with respiratory disease, including 243 (39\%) patients with COPD. There were no in-flight deaths but one patient died within 4 weeks post-travel. During the flight, only $18 \%$ of patients experienced mild respiratory distress. ${ }^{87}$ COPD patients are at a high risk of VTE due to limited mobility, inflammation, hypobaric hypoxia and comorbidities. ${ }^{93,94}$ VTE events can play a role in acute exacerbations of COPD. ${ }^{95}$ Thus, this category of travellers should avoid an excessive alcohol intake, sedatives, dehydration, and cigarette smoking. They should keep themselves active during air travel and at their travel destination. ${ }^{32,85}$

\section{Asthma}

Asthma is the most common respiratory condition reported by travellers. ${ }^{32}$ Patients with well-controlled asthma can travel safely. Patients with uncontrolled asthma or with a recent exacerbation should be warned against travel until their condition is completely controlled. ${ }^{32}$ It is vital that patients should not interrupt their usual treatment during the journey and that they should carry a short-acting inhaler and a short course of rescue oral steroids in case of an emergency during their journey. ${ }^{96-99}$ Bronchospasm induced by bronchial mucosal dryness as a result of weather changes, dehydration and low humidity in the in-flight cabin are the main risk factors for those who travel with asthma. ${ }^{100,101}$ It is sometimes challenging to differentiate true asthma exacerbations from dyspnoea secondary to hyperventilation or panic attacks. ${ }^{101,102}$

Severe asthma attacks during travel remain rare, although deaths have been reported. ${ }^{66,85,102} \mathrm{~A}$ British study reported that respiratory attacks accounted for $21 \%$ of all medical events occurring in travellers with a pre-existing medical condition. One third of those suffering from an asthma exacerbation had forgotten to take their medication. ${ }^{102}$ Similarly, Dowdall ${ }^{103}$ reported asthma as the most frequently occurring respiratory condition on flights completed by a major international airline. Most episodes were mild and resulted from having left their medication in the hold baggage. In the UK Flight Outcomes Study, 15\% of the travellers had asthma. No deaths were reported in this group. While there was a worsening of dyspnoea and a need for antibiotics after travel, the authors 
determined that asthmatic patients were not particularly at risk. Thus, they concluded that air travel is generally safe for patients with well-controlled asthma. ${ }^{87}$

\section{Interstitial Lung Disease}

Research remains limited regarding the experiences of travellers with interstitial lung disease (ILD). However, current data suggests that travelling with ILD deserves a detailed evaluation and pre-travel consideration. An Australian study investigated the effect of simulated cabin altitude on 15 patients with ILD at rest and during a limited $(50 \mathrm{~m})$ walking test. There was a significant drop in oxygen saturation (mean $\mathrm{SpO}_{2} 87 \%$ and $\mathrm{PaO}_{2} 6.8 \mathrm{kPa}$ ) which worsened during the walking test (mean $\mathrm{SpO}_{2} 79.5 \%$ and $\mathrm{PaO}_{2} 5.5 \mathrm{kPa}$ ) despite normal resting oxygen saturation at sea level. ${ }^{92}$ Patients with ILD were more likely than other respiratory patients to visit their healthcare provider for respiratory care within a month of their travel. ${ }^{87}$

Travellers with ILD should also be properly assessed for comorbidities and their risk of developing a respiratory tract infection. They may need to carry a short course of antibiotics and steroids. They also need to be advised about the importance of vaccination prior to travel. Health care providers should counsel patients who are on a new generation of anti-fibrotic agents (e.g. Pirfenidone) about the risk of severe sunburn and skin photosensitivity associated with use of this agent. ${ }^{84,85,104,105}$

\section{Cystic Fibrosis}

A comprehensive review by the European Centres of Reference Network for Cystic Fibrosis (ECORN-CF) in 2010 detailed the steps and recommendations for both patient and heath care providers in terms of travelling with cystic fibrosis (CF). ${ }^{106}$ Since then, there has been only a limited amount of data available on the travel healthcare needs and risks of patients with CF. According to a recent survey of 100 patients attending an adult CF Centre in the UK, 96\% had travelled abroad. Some $18 \%$ had no travel insurance and $23 \%$ had insurance that did not cover their primary illness. Only $10 \%$ of travellers experienced a CF-related illness (there were 7 respiratory tract infections, 2 who suffered from dehydration and 1 that developed pancreatitis) and $12 \%$ reported a nonCF-related illness. Four CF travellers had sunburn, three developed gastroenteritis, there were three ear infections, one experienced a fall, and one reported gastro-oesophageal reflux. $^{107}$

Patients with pulmonary CF are at risk of developing hypoxaemia during flight, high attitude and during exercise. ${ }^{108,109}$ Spirometry and HCT predicted altitude-induced hypoxaemia; however, there is some discrepancy between both tests in estimation of the level of hypoxaemia in these patients. ${ }^{85,110-113}$ Patients with CF who are travelling to low humidity areas may have a greater risk of bronchospasm and mucus plugs leading to lung collapse. Hence, it is imperative that they keep themselves well hydrated throughout their trip. ${ }^{114}$ It is also advisable to avoid travelling in groups due to risk of cross infection from other CF patients. ${ }^{115}$ Some studies have shown an increase in exacerbation post-travel due to the poor management of the disease. ${ }^{116,117}$ Full compliance with recommended treatment and physiotherapy reduces the risk of complications (Table 2). ${ }^{106,118}$

\section{Diabetes Mellitus}

Diabetes is primarily a self-managed disease. However, travel abroad can be uniquely challenging for many patients due to several factors including the time zone, weather, diet and living condition changes. ${ }^{26,119-122}$ Approximately 15\% of travellers with insulin-treated diabetes stated that their choice of travel destination was affected by their use of insulin, particularly in terms of avoiding long-haul travel and developing countries. ${ }^{119}$ Nonetheless, travellers with diabetes can travel safely if they are adequately prepared. A survey of 47 young adults with type 1 diabetes (T1DM) and 48 controls who had completed 154 international trips demonstrated that travellers with T1DM did not develop more travel-related

Table 2. Practical Recommendations for Travel With Respiratory Disease

\begin{tabular}{|c|c|}
\hline Respiratory Condition & Practical Recommendations \\
\hline $\begin{array}{l}\text { Chronic obstructive airway } \\
\text { disease/Asthma }\end{array}$ & $\begin{array}{l}\text { Carry adequate inhaler supply } \\
\text { Carry emergency supply of antibiotics and steroids } \\
\text { Careful assessment prior to travel for oxygen supplementation. } \\
\text { Up to date vaccinations including the flu vaccine. }\end{array}$ \\
\hline Interstitial lung disease & $\begin{array}{l}\text { Careful full pre-travel assessment and oxygen supplementation if engaging in high-altitude travel. } \\
\text { Carry an emergency supply of antibiotics and steroids. }\end{array}$ \\
\hline Pneumothorax & $\begin{array}{l}\text { A chest } \mathrm{x} \text {-ray must be done for any patient who has had pneumothorax to confirm its complete resolution before flight. } \\
\text { Travel should be delayed to } 14 \text { days post-resolution. }\end{array}$ \\
\hline Cystic fibrosis & $\begin{array}{l}\text { Encourage hydration to avoid dryness of the airway and thickened secretions. } \\
\text { Use a nebulizer, if airlines allow, for long-haul journeys. } \\
\text { Chest physiotherapy exercises should be performed pre- and during long journeys. } \\
\text { Additional vaccinations may be needed, depending on the destination. } \\
\text { CF medication may need adaptations according to climate change. } \\
\text { Carry CF specific insurance and health information as well as all necessary contact data. }\end{array}$ \\
\hline Obstructive sleep apnoea & $\begin{array}{l}\text { Avoid sedative drugs and alcohol. } \\
\text { CPAP device should be operable at altitude and with a power supply at the destination. } \\
\text { Use dry-cell batteries in-flight. }\end{array}$ \\
\hline
\end{tabular}




\section{Box 2. Practical Recommendations for Travellers With Diabetes}

General Advice

- Carry extra supplies of all drugs, glucose and ketone monitoring equipment.

- Carry a medical letter or identity card with details of your condition, medication and a contact number in case of emergency.

- $\quad$ Carry simple carbohydrates in case of a hypoglycaemic event.

- Check blood glucose frequently, particularly if there is a significant change in physical activity, diet and/or sleep.

- Avoid exposing blood glucose and insulin devices to extreme environments.

Foot Care

- Inspect and look after your feet at all times.

- Wear comfortable footwear.

- Wear supportive cotton socks.

- Make sure to dry in between your toes before wearing shoes.

- Avoid prolonged immobilisation.

- $\quad$ Avoid walking barefoot, especially on hot pavements.

\section{Sick Day Rules}

- Make sure to get enough rest and to keep well hydrated.

- Monitor your blood sugars more often and seek medical advice for high readings.

- Carry an emergency kit of commonly used drugs such antipyretics, antihistamines and an oral rehydration solution (ORS).

\section{Insulin}

- $\quad$ Carry a sufficient insulin supply to cover the entire trip.

- Keep insulin stored properly. Insulin pens can be stored at room temperature.

- Keep insulin in accessible locations at all times, i.e. cabin baggage.

- Dose adjustments and correction should be guided by selfblood glucose monitoring.

- Insulin pump users should carry short-acting and basal insulin pens in case of an emergency.

\section{Oral Anti-diabetic Mediations}

- No dose adjustment is needed during travel for non-insulin glucose lowering drugs.

- $\quad$ Patients on sulphonylureas need to have at least three meals a day to avoid the risk of hypoglycaemic episodes.

- Patients on SGLT2 inhibitors need to keep themselves wellhydrated and stop taking their medication in the event of intercurrent illness to avoid the risk of ketoacidosis.

Adapted from Nassar et al, ${ }^{130}$ and Jawad and Kalra ${ }^{140}$

illnesses than healthy travellers. They had an acceptable level of glycaemic control during their trips without metabolic consequences. ${ }^{123}$

There are several published guidelines regarding international travel with diabetes. ${ }^{124-127}$ These sources are generally in agreement in relation to the advice that they provide (Box 2). The management of diabetes is based on a 24-hour cycle. When travelling across fewer than five time zones, there is no need for an insulin dose adjustment. ${ }^{128,129} \mathrm{~A}$ specific dose adjustment is required for travel involving at least five time zones. ${ }^{129}$ Timing is less important when travelling on oral anti-diabetic medications, expect for sulfonylurea agents. Patients should be educated not to take sulphonylureas if they are going to miss meals. Other oral agents (e.g. metformin, SGLT2 inhibitors, GLP1 agonists, DPP4 inhibitors and thiazolidinediones) may be continued as they rarely cause hypoglycaemic episodes. ${ }^{130,131}$

Warm climate destinations can significantly affect diabetic medications, supplies and equipment. ${ }^{132-134}$ Patients taking insulin or GLP1 agonists should check the availability of refrigeration equipment on the airplane and at their destination. Colder environments can also potentially degrade diabetes medications and supplies. If ice crystals are found in insulin vials, the affected vial should be discarded. ${ }^{135}$ Diabetic travellers should be advised to wear protective clothing such as hats, sunglasses, sunscreen, gloves, and comfortable footwear so then they can enjoy their journey without the risk of heat exhaustion, cold exposure or foot injuries. ${ }^{122,130,135}$

Food options for diabetic travellers can be also be a challenging issue during travel. ${ }^{136}$ Diabetic travellers should choose their own meals during air travel. They should carry healthy snacks at all times to prevent or treat episodes of hypoglycaemia. ${ }^{137}$ When travelling to non-English speaking countries, food labels and menus can be difficult to interpret, particularly for diabetic travellers who use carbohydrate counting. Hence advanced planning using internet-based resources and seeking formal advice from a dietician prior to travel can benefit these travellers. ${ }^{138}$

Physical activities including walking usually increase during travel and this may increase glucose utilisation and insulin absorption. This can lead to a decrease in the patient's blood glucose level. Thus diabetic travellers should monitor their blood glucose levels more frequently. ${ }^{139,140}$ They should also be advised to wear comfortable footwear to reduce the occurrence of blisters and abrasions. ${ }^{139}$ Travellers should remain well-hydrated and check the quality of the drinking water available at their travel destination to reduce their risk of traveller's diarrhoea and dehydration. ${ }^{139,141}$

\section{Neurological Conditions}

Epilepsy and Seizure Disorders

The avoidance of in-flight seizures in travellers with epilepsy remains the primary consideration. The occurrence of generalised tonic-clonic seizures in confined aircraft cabin conditions may be fatal due to the higher risk of developing status epilepticus and the compromise of the airway. ${ }^{142,143}$ Therefore, it is strongly recommended that emergency anticonvulsant medications should be an essential component of all airline medical kits. ${ }^{143}$ Air travel is contraindicated in recurrent and uncontrolled fits. ${ }^{144}$ The patient should be strongly advised to avoid sleep deprivation and alcohol misuse as both may lower their seizure threshold. They should also be strictly adherent to their antiepileptic medication regimen. An adequate and accessible supply of medication should be assured during a long-haul flight. ${ }^{142}$

\section{Transient Ischaemic Attack and Stroke}

The avoidance of non-essential travel is recommended 
in patients with frequent or crescendo transient ischemic attacks. ${ }^{142}$ Individuals following a recent stroke should wait at least 2 to 4 weeks before their travel or until their condition has stabilised, depending on the severity. ${ }^{142}$ The issue of non-urgent travel after an ischemic stroke is complex. Unfortunately, there is little data available to guide physicians. We recommend that further research in this field is needed to provide evidence-based advice to travelling patients after a recent cerebrovascular event. It is suggested that stroke patients with a full neurological recovery or minimal deficits who are capable of managing their daily activities with minimal assistance can safely travel without the need for a medical escort. ${ }^{145}$

\section{Parkinson's Disease and Other Movement Disorders}

The effect of long travel in patients with advanced movement disorders has been less well studied. A single study reported the reversible worsening of neuropsychiatric, motor and non-motor symptoms after travelling by air or land (coach trips) exceeding four hours in each of the five patients with an advanced movement disorder. ${ }^{146}$ All reported cases experienced a worsening of their motor and cognitive functions with a failure response to their regular treatment. The episodes lasted 2 to 5 days. Two patients reported drinking less fluid while on the flight while others reported poor sleep and an erratic drug regimen during travel. ${ }^{146}$ Patients should be advised regarding long haul travel. Appropriate prophylactic measures such as advice on hydration, the timing of medication and sleep may need to be instituted. They also should seek airport assistance for gate access. Aircraft entry and convenient seating arrangements are necessary for travellers with movement disorders. Pre-arranged seating can help to assure timely access to the lavatory facilities. ${ }^{142,147}$

\section{Autoimmune Neurological Disorders}

Neurological diseases such as multiple sclerosis, Guillain-Barré syndrome and myasthenia gravis often create management problems for travel medicine physicians. ${ }^{147}$ These conditions could be exacerbated either by naturally acquired infections or by vaccinations and anti-malarial medication. ${ }^{148,149}$ The patients should receive all recommended vaccinations with the exception of the yellow fever vaccine which is contraindicated in myasthenia gravis. As a consequence, those patients should avoid yellow fever endemic areas. ${ }^{150}$ Furthermore, most antimalarial agents can worsen or induce myasthenia gravis. ${ }^{151}$ Atovaquone-proguanil remains the safest option for malaria chemoprophylaxis in these patients. ${ }^{150}$

\section{Chronic Kidney Disease}

The risk of developing an illness while travelling abroad depends on several factors including the stage of chronic kidney disease (CKD), the age of the traveller, the travel destination, the duration of their stay and the nature of any planned activities. ${ }^{152}$ The Centre for Disease Control and Prevention (CDC) website offers information to address the health risks that a traveller with CKD may face. It also summarises the travel vaccines recommended for these travellers. ${ }^{152}$ Some CKD and dialysis travellers will still develop an illness despite their health care providers' best efforts. A single six-month prospective study investigated the incidence of travel-related morbidity for patients on haemodialysis. Antibiotic use in addition to their biochemical and microbiological parameters were collected for 3 months pre- and post-dialysis abroad. A total of 172 individuals travelled on 200 separate occasions. The rate of central venous catheter infection was $0.25 / 1000$ for the three months pretravel compared to $0.83 / 1000$ in the post-travel period. The need for oral and parenteral antibiotics for bacterial infection was significantly higher post-travel. There was no evidence of hepatitis B or hepatitis C seroconversion. The authors concluded that travel and dialysis away from a patient's usual haemodialysis unit is associated with an increased risk of bacterial infection, anaemia, and inflammatory response. ${ }^{153}$

Finding reliable and timely medical care service during travel can be challenging in many international destinations. For CKD and post-transplant patients, it is important to emphasise food and water precautions, in addition to planning for the self-management of dehydration which can worsen renal function. Arranging for dialysis abroad if such a situation arises is also a sensible step to take. For chronic renal failure, it is especially important to vaccinate against influenza, pneumococcal disease and hepatitis B. ${ }^{152,154,155}$ Patients on a low sodium diet should notify their travel agency, airlines, and hotels in good time prior to their departure.

A worldwide listing of dialysis centres can be obtained via the website www.globaldialysis.com. As most dialysis centres around the world have a busy schedule, arrangements for dialysis at these facilities must be done in advance through the patient's centre and social worker. However, most centres can provide emergency treatment. ${ }^{2}$ Knotek and Biel offer a guide to help travel planning for peritoneal dialysis patients. ${ }^{156}$

\section{Mental Health Disorders}

Individuals with a pre-existing mental health disorder rarely seek pre-travel health advice so the prevention of any acute exacerbation occurring during travel is difficult. ${ }^{157-159}$ Travel medicine physicians often have little experience in dealing with these disorders as they tend to focus on infectious diseases. ${ }^{160}$ It was reported that around $11 \%$ of travellers could experience some kind of psychiatric disorder with $2.5 \%$ suffering a severe psychotic episode and $1.2 \%$ requiring over two months of therapy on the return home. ${ }^{161,162}$ Acute psychotic episodes comprise one fifth of all travel-related psychiatric problems. Psycho-organic disorders during leisure activities represent $5 \%$ of all travel-related problems. ${ }^{163}$ Alcohol is often used to alleviate travel-related fears and anxiety. This in itself can worsen travel-associated mental health disorders. ${ }^{164}$ Alcohol and drugs misuse can worsen psychiatric symptoms and increase the risk of accident and assaults. They can also aggravate dehydration, motion sickness, and heat stress. ${ }^{165}$ Jet lag can aggravate psychiatric conditions by precipitating de novo psychosis and disrupting the biological circadian system. ${ }^{166}$ Circadian disruption, insomnia, and sleep-related problems in patients with schizophrenia may also be due 
to melatonin deficiency, leading to an over-activity of the dopamine system. ${ }^{167}$ A Cochrane systematic review found that the short-term use of melatonin can be safe and effective in the prevention of jet lag. ${ }^{168}$ It is recommended to take a single dose of 2 to $5 \mathrm{mg} 2$ to 3 hours before bedtime and up to 4 days after arrival at the traveller's destination. Melatonin decreases the latency of sleep onset and increases sleep efficiency and duration. ${ }^{169}$ It also has an antidepressant effect which may be useful for vulnerable travellers. ${ }^{170}$

Travel medicine specialists should be aware of the side effects of antipsychotic medications. Travellers who are taking antipsychotic medications are at a higher risk of developing VTE on long-haul flights. ${ }^{171}$ Some antipsychotic agents can also cause photosensitivity skin reactions from sun exposure that can be misinterpreted in a delusional way. ${ }^{172}$ Travel health professionals should also be aware that some anti-malarial agents such as mefloquine can elicit psychotic symptoms that can last for several weeks. ${ }^{173-175}$ Travellers with a pre-existing psychiatric condition should carry a copy of their prescription and an explanatory letter from their physician. This can be useful as some countries can refuse entry to those with a history of psychosis. Travellers should also carry an adequate medication supply and keep them easy to access during their trip (Box 3). Mental health professionals should liaise with their colleagues at the traveller's destination so then the traveller can gain access to psychiatric services if needed. ${ }^{176}$ Arrangements need to be made in advance for these travellers regarding depot antipsychotic injections due to the need for a receipt for the medication at the traveller's destination. The monitoring of blood tests also needs to be arranged for those taking clozapine or lithium. Clozapine is usually dispensed in limited amounts that only cover the period between blood tests. Therefore, it is crucial to dispense the medication for the whole travel period because the interruption of clozapine

\section{Box 3. Practical Advice for Travellers With a Psychiatric Disorder}

- Ensure that the travel insurance can cover medical evacuation for psychiatric disorders.

- Carry an adequate supply of medicine and keep medicines in more than one location.

- Ensure where and how you can obtain a new supply of medicine.

- Avoid travel medicines that can exacerbate psychiatric conditions unless a specialist physician approves. Take an alternative to mefloquine if malaria prophylaxis is needed. Be cautious about the use of chloroquine. Avoid taking modafinil or similar drugs for jet lag. Be sparing in the use of zolpidem and other sleep-inducing medications that can affect memory and perception.

- Attend to sleep; minimise the effects of jet lag due to exposure to light and take melatonin on a short-term basis.

- Anticipate cultural changes to minimise a sense of cultural displacement.

- Carry anti-anxiety medication to use in the case of a panic attack.

- Plan for a consultation with your own psychiatrist on your return.

Adapted from Sanford et al. ${ }^{26}$ doses can lead to a rapid relapse of psychosis. ${ }^{177}$ Most travel insurance policies exclude the treatment and repatriation costs incurred due to acute mental illness. ${ }^{178}$ However, the availability of a repatriation protocol and the appropriate preparation of individuals with pre-existing mental health conditions should lessen the reluctance of travel insurance companies to cover these patients. ${ }^{176}$

\section{Travelling With Chronic Medication Use}

It is important to recognise the barriers to appropriate and safe pharmacotherapy when crossing international borders and how can these be minimised. Barriers can include access to refills, the availability of medication, limited insurance coverage and foreign languages, all of which may lead to adverse drug events. ${ }^{179}$ In addition to the symptoms of jet lag, crossing several time zones can challenge the timing of medication use. ${ }^{180} \mathrm{~A}$ scheduled medical evaluation prior to travel is recommended and may help to remove some of the barriers. During the evaluation, long-term medications are reviewed and adapted to the medical condition as well as to the travel destination, travelling time and mode of travel. ${ }^{181}$

\section{Anticoagulants}

Although the newer direct oral anticoagulants currently have a very specific indication, they offer a better option than warfarin for travelling patients because of their quicker onset of action, fewer drug-food interactions and the lack of necessity for regular international normalised ratio monitoring. ${ }^{182,183}$ Nonetheless, warfarin still presents the best option for patients with end-stage renal disease. In patients with a history of falling, the newer agents may not be preferable to warfarin because of the lack of a well-accepted reversal protocol. ${ }^{184}$ One of the convenient characteristics of warfarin is its once-daily dose. However, this needs to be constantly adjusted depending on the coagulation profile. ${ }^{184}$ In contrast, both dabigatran and apixaban require twice-daily dosing, ${ }^{183}$ making them less desirable for travelling patients. Rivaroxaban and edoxaban may prove to be the best options for promoting patient compliance because of their once-daily dosing regimen. ${ }^{182}$ In circumstances in which the patients' greatest fear is bleeding and he/she is less concerned with the potential consequences of VTE, it may be better to hold off on treatment and to make contact with their primary care doctor to discuss plans for starting anticoagulation after the travel is complete. ${ }^{185}$

\section{Proton Pump Inhibitors}

Chronic proton pump inhibitor use can cause severe hypochlorhydria and this can lead to bacterial colonisation and an increased risk of developing an entering bacterial infection. ${ }^{186}$ Therefore, physicians should be aware of this clinical implication. They should consider alternative therapeutic options for travellers who are departing to areas with a higher incidence of diarrhoea. ${ }^{187}$

\section{Contraception}

The timing of the oral contraceptive pill (OCP) intake can be 
impacted when travel traverses time zones, particularly for women taking the progesterone-only pill. ${ }^{8}$ Its effectiveness can decrease when flying west where the time is prolonged between doses. ${ }^{188}$ Travellers taking the OCP can set a second watch to their home time to avoid confusion with timing. ${ }^{188}$ The risk of travel-related VTE is increased by the combined contraceptive pill. Travellers should follow the standard preventive measures which include exercises and maintaining hydration. Below-knee compression stockings should also be considered for long-haul air passengers taking the OCP. ${ }^{189}$

\section{Coronavirus Disease 2019 (COVID-19) and Chronic Medical Illness}

In December 2019, an outbreak of severe acute respiratory coronavirus 2 (SARS-CoV-2) infection was reported in Wuhan, Hubei province, China. ${ }^{190}$ Since then, the infection has spread to nearly 175 countries around the world and reached pandemic status. The outbreak has already led to catastrophic outcomes among the patients with a pre-existing medical condition. Poorer clinical outcomes and higher death rates have been observed in patients with pre-existing medical conditions, especially HTN, diabetes, and CVD, all of which are more common in older patients. ${ }^{191}$ There are also concerns about the impact of the pandemic on the routine management of patients with a chronic illness. It is believed that the pandemic could last for months and even years until a safe and protective vaccine can be developed. How routine leisure and business international travel will gradually emerge remains to be seen in the coming year. A detailed exploration of the COVID-19 pandemic and its impact on travellers with a chronic illness is beyond the scope of the current review. The data is still quite limited, but we anticipate that further studies will evaluate the risk of travel with a pre-existing medical condition during the COVID-19 pandemic era and produce evidence-based guidance for travellers.

\section{Discussion}

As the population ages and the ability to care for patients with a pre-existing medical condition improves, the number of travellers with a pre-existing condition is likely to continue to increase every year. This review attempted to critically discuss the practical challenges, health risks that encounter travellers with a chronic illness. We also included the most recent evidence-based recommendations and practical guidance for travelling with a wide range of common and important medical illnesses. A summary of the major recommendations relating to travelling with chronic illnesses is presented in Tables 1-5. However, our coverage cannot be considered exhaustive and relevant disorders which have been omitted from this work. This review did not address travelling with pregnancy, physical disability, or immunocompromised travellers. As these conditions have already been discussed thoroughly in the current literature.

Traveller with a pre-existing illness should know the details of their planned trip, to be familiar with standard precautions and recommendations for travelling with such illness and recognise the symptoms of decompensation of their illness.

\section{Review Highlights}

\section{What Is Already Known?}

Pre-existing medical conditions such as cardiovascular disease (CVD), diabetes mellitus (DM) and chronic respiratory conditions have the potential to complicate international travel. The majority of travel-associated illness is thought to be due to decompensation of preexisting medical conditions

\section{What Does This Study Add?}

We provide a comprehensive narrative review that addresses the challenges encountered by travellers with each of these conditions. We have done our best to be current in our discussions by including recently updated and evidence-based practical approaches for travel with each of these chronic conditions, while acknowledging the need for further research in this field.

For people with pre-existing medical illness, the risk of decompensation in the absence of potential medical support can be significant and must be taken seriously. Contrary, with proper planning and precautions, many individuals with preexisting illness can enjoy a safe travel. Eventually, avoidance of potential risky and complicated trip must be carefully considered against the benefits of taking such kind of trip. Travellers and their physicians should work together for a more individualised and safe pre-travel plan.

This review is subject to limitations. First, the search was limited to English language articles published in the selected databases. We did not conduct a search for articles published in other languages. Only the references of articles that were available in full text were included.

\section{Conclusion}

Travel is generally safe for most individuals with a stable medical condition. However, a systematic understanding of the challenges that may arise during travel is critical given the higher risk of complications in travellers with a pre-existing medical condition and their associated potential impact. It is imperative for health care providers to be aware of the preventative measures and current recommendations that should be taken before and during travel to protect individuals with a chronic illness. Guidelines and recommendations should be continued to be up to dated and directed to protect this vulnerable group of travellers.

\section{Authors' Contributions}

MD contributed to conception, design, data collection and writing up the manuscript. GF contributed to conception, design, supervision, and critically review of the manuscript before final submission.

\section{Conflict of Interest Disclosures}

The authors declare that they have no conflicts of interest.

\section{Ethical Approval}

Not applicable. 


\section{Funding/Support}

None.

\section{References}

1. World Tourism Organization (UNWTO). Tourism Towards 2030: Global Overview. Madrid: UNWTO; 2011.

2. McCarthy A, Burchard GD. The traveler with preexisting disease. In: Keystone JS, Kozarsky PE, Connor BA, Nothdurft HD, Mendelson M, Leder K, eds. Travel Medicine. 4th ed. London: Elsevier; 2019. p. 261-267. doi:10.1016/B978-0-32354696-6.00026-4.

3. Wieten RW, Leenstra T, Goorhuis A, van Vugt M, Grobusch MP. Health risks of travelers with medical conditions--a retrospective analysis. J Travel Med. 2012;19(2):104-110. doi:10.1111/j.1708-8305.2011.00594.x.

4. Hochberg NS, Barnett ED, Chen LH, et al. International travel by persons with medical comorbidities: understanding risks and providing advice. Mayo Clin Proc. 2013;88(11):1231-1240. doi:10.1016/j.mayocp.2013.07.018.

5. United Nations Department of Economic and Social Affairs (DESA). World Population Prospects: The 2015 Revision, Key Findings and Advance Tables. New York: DESA; 2015.

6. LaRocque RC, Rao SR, Lee J, et al. Global TravEpiNet: a national consortium of clinics providing care to international travelers-analysis of demographic characteristics, travel destinations, and pretravel healthcare of high-risk US international travelers, 2009-2011. Clin Infect Dis. 2012;54(4):455-462. doi:10.1093/ $\mathrm{cid} / \mathrm{cir} 839$.

7. Bühler S, Rüegg R, Steffen R, Hatz C, Jaeger VK. A profile of travelers--an analysis from a large swiss travel clinic. J Travel Med. 2014;21(5):324-331. doi:10.1111/jtm.12139.

8. Moore P, Streeton C. Oral hormonal contraception in special circumstances. Aust Fam Physician. 2017;46(10):728-732.

9. Sanford CA. Centers for Disease Control and Prevention Yellow Book 2018: Health Information for International Travelers. Am J Trop Med Hyg. 2018;98(4):1209. doi:10.4269/ajtmh.17-0987.

10. Mileno MD, Suh KN, Keystone JS, Bia FJ. Special high-risk travel groups: immunocompromised, older, disabled and chronically ill travelers. In: Zuckerman JN, ed. Principles and Practice of Travel Medicine. Chichester, UK: John Wiley and Sons; 2001. p. 431-445. doi:10.1002/0470842512.ch26.

11. Fenner P. Fitness to travel-assessment in the elderly and medically impaired. Aust Fam Physician. 2007;36(5):312-315.

12. Herman J, Patel D. Advising the traveller. Medicine (Abingdon). 2018;46(1):59-65. doi:10.1016/j.mpmed.2017.10.004.

13. Hamer DH, MacLeod WB, Chen LH, et al. Pretravel health preparation of international travelers: results from the Boston area Travel Medicine Network. Mayo Clin Proc Innov Qual Outcomes. 2017;1(1):78-90. doi:10.1016/j. mayocpiqo.2017.04.001.

14. Naouri D, Lapostolle F, Rondet C, Ganansia O, Pateron D, Yordanov Y. Prevention of medical events during air travel: a narrative review. Am J Med. 2016;129(9):1000.e1-6. doi:10.1016/j.amjmed.2016.05.013.

15. Steffen R, DuPont HL, Wilder-Smith A. Manual of Travel medicine and Health. Shelton: PMPH USA; 2007. p. 331-347.

16. Chen LH. The pre-travel consultation. In: CDC Health Information for International Travel. New York: Oxford University Press; 2014. p. 26-32.

17. Mahadevan SV, Strehlow MC. Preparing for international travel and global medical care. Emerg Med Clin North Am. 2017;35(2):465-484. doi:10.1016/j.emc.2017.01.006.
18. Kloner RA. Natural and unnatural triggers of myocardial infarction. Prog Cardiovasc Dis. 2006;48(4):285-300. doi:10.1016/j.pcad.2005.07.001.

19. US Department of Commerce, International Trade Administration, Office of Travel and Tourism Industries. US Citizens Air Traffic to Overseas, Canada, and Mexico 2009. http://tinet.ita.doc.gov/view/m-2009-O-001/index.html. Accessed July 18, 2019.

20. Kop WJ, Vingerhoets A, Kruithof GJ, Gottdiener JS. Risk factors for myocardial infarction during vacation travel. Psychosom Med. 2003;65(3):396-401. doi:10.1097/01. psy.0000046077.21273.ec.

21. Office for National Statistics. Travel Trends 2009: A Report on the 2009 International Passenger Survey. Office for National Statistics; 2009.

22. Nable JV, Tupe CL, Gehle BD, Brady WJ. In-flight medical emergencies during commercial travel. N Engl J Med. 2015; 373(10):939-945. doi:10.1056/NEJMra1409213.

23. Cocks R, Liew M. Commercial aviation in-flight emergencies and the physician. Emerg Med Australas. 2007;19(1):1-8. doi:10.1111/j.1742-6723.2006.00928.x.

24. Krantz DS, Sheps DS, Carney RM, Natelson BH. Effects of mental stress in patients with coronary artery disease: evidence and clinical implications. JAMA. 2000;283(14):1800-1802. doi:10.1001/jama.283.14.1800.

25. Possick SE, Barry M. Air travel and cardiovascular disease. J Travel Med. 2004;11(4):243-248. doi:10.2310/7060.2004.19009.

26. Sanford CA, Jong EC, Pottinger PS. The Travel and Tropical Medicine Manual E-Book. Elsevier Health Sciences; 2016. p. 664.

27. Keystone JS, Kozarsky PE, Connor BA, Nothdurft HD, Mendelson M, Leder K. Travel Medicine E-Book. Elsevier Health Sciences; 2018. p. 568.

28. Possick SE, Barry M. Evaluation and management of the cardiovascular patient embarking on air travel. Ann Intern Med. 2004;141(2):148-154. doi:10.7326/0003-4819-141-2200407200-00014.

29. Amsterdam EA, Wenger NK, Brindis RG, et al. 2014 AHA/ACC guideline for the management of patients with non-ST-elevation acute coronary syndromes: a report of the American College of Cardiology/American Heart Association Task Force on Practice Guidelines. J Am Coll Cardiol. 2014;64(24):e139-e228. doi:10.1016/j.jacc.2014.09.017.

30. O'Gara PT, Kushner FG, Ascheim DD, et al. 2013 ACCF/AHA guideline for the management of ST-elevation myocardial infarction: a report of the American College of Cardiology Foundation/American Heart Association Task Force on Practice Guidelines. J Am Coll Cardiol. 2013;61(4):e78-e140. doi:10.1016/j.jacc.2012.11.019.

31. Steg PG, James SK, Atar D, et al. ESC Guidelines for the management of acute myocardial infarction in patients presenting with ST-segment elevation. Eur Heart J. 2012;33(20):2569-2619. doi:10.1093/eurheartj/ehs215.

32. Medical guidelines for airline travel, 2nd ed. Aviat Space Environ Med. 2003;74(5 Suppl):A1-19.

33. UK Civil Aviation Authority. Assessing Fitness to Fly. Guidelines for Medical Professionals from the Aviation Health Unit. UK Civil Aviation Authority; 2007.

34. Ross D, Essebag V, Sestier F, et al. Assessment of the cardiac patient for fitness to fly: flying subgroup executive summary. Can J Cardiol. 2004;20(13):1321-1323.

35. Pearce E, Haffner F, Brady LB, et al. Nonurgent commercial 
air travel after acute coronary syndrome: a review of 288 patient events. Air Med J. 2014;33(5):222-230. doi:10.1016/j. amj.2014.04.013.

36. Novaro GM, Bush HS, Fromkin KR, et al. Cardiovascular emergencies in cruise ship passengers. Am J Cardiol. 2010; 105(2):153-157. doi:10.1016/j.amjcard.2009.09.004.

37. Contributions of mean and shape of blood pressure distribution to worldwide trends and variations in raised blood pressure: a pooled analysis of 1018 population-based measurement studies with 88.6 million participants. Int J Epidemiol. 2018;47(3):872883i. doi:10.1093/ije/dyy016.

38. Kearney PM, Whelton M, Reynolds K, Muntner P, Whelton PK, He J. Global burden of hypertension: analysis of worldwide data. Lancet. 2005;365(9455):217-223. doi:10.1016/s01406736(05)17741-1.

39. Stienlauf S, Streltsin B, Meltzer E, et al. Chronic illnesses in travelers to developing countries. Travel Med Infect Dis. 2014;12(6 Pt B):757-763. doi:10.1016/j.tmaid.2014.10.004.

40. Alon D, Shitrit P, Chowers M. Risk behaviors and spectrum of diseases among elderly travelers: a comparison of younger and older adults. J Travel Med. 2010;17(4):250-255. doi:10.1111/ j.1708-8305.2010.00425.x.

41. Darrat M, Flaherty GT. Retrospective analysis of older travellers attending a specialist travel health clinic. Trop Dis Travel Med Vaccines. 2019;5:17. doi:10.1186/s40794-019-0094-8.

42. Luks AM. Should travelers with hypertension adjust their medications when traveling to high altitude? High Alt Med Biol. 2009;10(1):11-15. doi:10.1089/ham.2008.1076.

43. Frizelle F. The older Traveller: a guide for the health professional. N Z Med J. 2018;131(1477):118-119.

44. Blood Pressure Monitoring. Managing Your Blood Pressure When Travelling Abroad. Blood Pressure Monitoring website. https://blood-pressure-monitoring.org/blood-pressure-whentravelling/. Published 2019.

45. Tareen N, Zadshir A, Martins D, Nagami G, Levine B, Norris KC. Alterations in acid-base homeostasis with aging. J Natl Med Assoc. 2004;96(7):921-925.

46. Lainscak M, Blue L, Clark AL, et al. Self-care management of heart failure: practical recommendations from the Patient Care Committee of the Heart Failure Association of the European Society of Cardiology. Eur J Heart Fail. 2011;13(2):115-126. doi:10.1093/eurjhf/hfq219.

47. Ponikowski P, Voors AA, Anker SD, et al. 2016 ESC Guidelines for the diagnosis and treatment of acute and chronic heart failure: the Task Force for the diagnosis and treatment of acute and chronic heart failure of the European Society of Cardiology (ESC). Developed with the special contribution of the Heart Failure Association (HFA) of the ESC. Eur J Heart Fail. 2016;18(8):891-975. doi:10.1002/ejhf.592.

48. Ingle L, Hobkirk J, Damy T, Nabb S, Clark AL, Cleland JG. Experiences of air travel in patients with chronic heart failure. Int J Cardiol. 2012;158(1):66-70. doi:10.1016/j.ijcard.2010.12.101.

49. Smith D, Toff W, Joy M, et al. Fitness to fly for passengers with cardiovascular disease. Heart. 2010;96 Suppl 2:ii1-16. doi:10.1136/hrt.2010.203091.

50. Hobkirk J, Damy T, Bennett A. Effects of Reduced Inspired Oxygen Concentration in Patients with Chronic Heart Failure. Proceedings of ESC; 2009.

51. Agostoni P, Cattadori G, Guazzi M, et al. Effects of simulated altitude-induced hypoxia on exercise capacity in patients with chronic heart failure. Am J Med. 2000;109(6):450-455. doi:10.1016/s0002-9343(00)00532-5.
52. Rimoldi SF, Sartori C, Seiler C, et al. High-altitude exposure in patients with cardiovascular disease: risk assessment and practical recommendations. Prog Cardiovasc Dis. 2010;52(6):512-524. doi:10.1016/j.pcad.2010.03.005.

53. Mieske K, Flaherty G, O’Brien T. Journeys to high altitude--risks and recommendations for travelers with preexisting medical conditions. J Travel Med. 2010;17(1):48-62. doi:10.1111/j.17088305.2009.00369.x.

54. Hackett PH, Wilkerson JA. Altitude and common medical conditions. In: Wilkerson JA, ed. Medicine for Mountaineering \& Other Wilderness Activities. 5th ed. Seattle, WA: Mountaineers Books; 2001. p. 240-258.

55. Izadi M, Alemzadeh-Ansari MJ, Kazemisaleh D, MoshkaniFarahani M. Air travel considerations for the patients with heart failure. Iran Red Crescent Med J. 2014;16(6):e17213. doi:10.5812/ircmj.17213.

56. Donegani E, Hillebrandt D, Windsor J, et al. Pre-existing cardiovascular conditions and high altitude travel. Travel Med Infect Dis. 2014;12(3):237-252. doi:10.1016/j. tmaid.2014.02.004.

57. Bradi AC, Faughnan ME, Stanbrook MB, Deschenes-Leek E, Chapman KR. Predicting the need for supplemental oxygen during airline flight in patients with chronic pulmonary disease: a comparison of predictive equations and altitude simulation. Can Respir J. 2009;16(4):119-124. doi:10.1155/2009/371901.

58. Howell MD, Geraci JM, Knowlton AA. Congestive heart failure and outpatient risk of venous thromboembolism: a retrospective, case-control study. J Clin Epidemiol. 2001;54(8):810-816. doi:10.1016/s0895-4356(00)00373-5.

59. Silverman D, Gendreau M. Medical issues associated with commercial flights. Lancet. 2009;373(9680):2067-2077. doi:10.1016/s0140-6736(09)60209-9.

60. Beri A, Mohan B, Sharma S, Gupta N, Sharma S. Travel concerns for congestive heart failure (CHF) patients. Internet J Health. 2010;11(1).

61. Hammadah M, Kindya BR, Allard-Ratick MP, et al. Navigating air travel and cardiovascular concerns: Is the sky the limit? Clin Cardiol. 2017;40(9):660-666. doi:10.1002/clc.22741.

62. Rosenthal T. Seasonal variations in blood pressure. Am J Geriatr Cardiol. 2004;13(5):267-272. doi:10.1111/j.10767460.2004.00060.x.

63. Luks AM, Swenson ER. Medication and dosage considerations in the prophylaxis and treatment of high-altitude illness. Chest. 2008;133(3):744-755. doi:10.1378/chest.07-1417.

64. Simpson C, Dorian P, Gupta A, et al. Assessment of the cardiac patient for fitness to drive: drive subgroup executive summary. Can J Cardiol. 2004;20(13):1314-1320.

65. Joy M. Cardiovascular disease and airline travel. Heart. 2007; 93(12):1507-1509. doi:10.1136/hrt.2007.134247.

66. Gendreau MA, DeJohn C. Responding to medical events during commercial airline flights. N Engl J Med. 2002;346(14):10671073. doi:10.1056/NEJMra012774.

67. Hainsworth R, Drinkhill MJ. Cardiovascular adjustments for life at high altitude. Respir Physiol Neurobiol. 2007;158(23):204-211. doi:10.1016/j.resp.2007.05.006.

68. Bärtsch P, Gibbs JS. Effect of altitude on the heart and the lungs. Circulation. 2007;116(19):2191-2202. doi:10.1161/ circulationaha.106.650796.

69. Pagé M, Sauvé C, Serri K, Pagé P, Yin Y, Schampaert E. Echocardiographic assessment of cardiac performance in response to high altitude and development of subclinical pulmonary edema in healthy climbers. Can J Cardiol. 
2013;29(10):1277-1284. doi:10.1016/j.cjca.2013.04.025.

70. Burtscher M, Pachinger O, Mittleman MA, Ulmer H. Prior myocardial infarction is the major risk factor associated with sudden cardiac death during downhill skiing. Int J Sports Med. 2000;21(8):613-615. doi:10.1055/s-2000-8481.

71. Dine CJ, Kreider ME. Hypoxia altitude simulation test. Chest. 2008;133(4):1002-1005. doi:10.1378/chest.07-1354.

72. Essebag V, Halabi AR, Churchill-Smith M, Lutchmedial S. Air medical transport of cardiac patients. Chest. 2003;124(5):19371945. doi:10.1378/chest.124.5.1937.

73. Kirchhof P, Benussi S, Kotecha D, et al. 2016 ESC Guidelines for the management of atrial fibrillation developed in collaboration with EACTS. Eur J Cardiothorac Surg. 2016;50(5):e1-e88. doi:10.1093/ejcts/ezw313.

74. Chugh SS, Havmoeller R, Narayanan K, et al. Worldwide epidemiology of atrial fibrillation: a Global Burden of Disease 2010 Study. Circulation. 2014;129(8):837-847. doi:10.1161/ circulationaha.113.005119.

75. Colilla S, Crow A, Petkun W, Singer DE, Simon T, Liu X. Estimates of current and future incidence and prevalence of atrial fibrillation in the U.S. adult population. Am J Cardiol. 2013;112(8):1142-1147. doi:10.1016/j.amjcard.2013.05.063.

76. Heeringa J, van der Kuip DA, Hofman A, et al. Prevalence, incidence and lifetime risk of atrial fibrillation: the Rotterdam study. Eur Heart J. 2006;27(8):949-953. doi:10.1093/eurheartj/ ehi825.

77. Krijthe BP, Kunst A, Benjamin EJ, et al. Projections on the number of individuals with atrial fibrillation in the European Union, from 2000 to 2060. Eur Heart J. 2013;34(35):2746-2751. doi:10.1093/eurheartj/eht280.

78. Al-Khatib SM, Stevenson WG, Ackerman MJ, et al. 2017 AHA/ACC/HRS guideline for management of patients with ventricular arrhythmias and the prevention of sudden cardiac death: a report of the American College of Cardiology/ American Heart Association Task Force on Clinical Practice Guidelines and the Heart Rhythm Society. J Am Coll Cardiol. 2018;72(14):e91-e220. doi:10.1016/j.jacc.2017.10.054.

79. Flaherty G, De Freitas S. A heart for travel: travel health considerations for patients with heart disease and cardiac devices. Ir Med J. 2016;109(10):486.

80. Lucas AM. Travel considerations for the cardiac patient. J Nurse Pract. 2012;8(7):540-546. doi:10.1016/j.nurpra.2012.01.015.

81. Roche NC, Thabouillot O, Bouvier F, Paule P. Prepare for takeoff: fasten your seatbelt and keep a magnet in your pocket! Prehosp Disaster Med. 2018;33(1):114-115. doi:10.1017/ s1049023x17007117.

82. Tissot C, Buchholz H, Mitchell MB, et al. First pediatric transatlantic air ambulance transportation on a Berlin Heart EXCOR left ventricular assist device as a bridge to transplantation. Pediatr Crit Care Med. 2010;11(2):e24-25. doi:10.1097/PCC.0b013e3181bc5974.

83. Haddad M, Masters RG, Hendry PJ, et al. Intercontinental LVAS patient transport. Ann Thorac Surg. 2004;78(5):18181820. doi:10.1016/j.athoracsur.2003.09.018.

84. Managing passengers with respiratory disease planning air travel: British Thoracic Society recommendations. Thorax. 2002; 57(4):289-304. doi:10.1136/thorax.57.4.289.

85. Ahmedzai S, Balfour-Lynn IM, Bewick T, et al. Managing passengers with stable respiratory disease planning air travel: British Thoracic Society recommendations. Thorax. 2011;66 Suppl 1:i1-30. doi:10.1136/thoraxjnl-2011-200295.

86. Ergan B, Akgun M, Pacilli AMG, Nava S. Should I stay or should
I go? COPD and air travel. Eur Respir Rev. 2018;27(148):180030. doi:10.1183/16000617.0030-2018.

87. Coker RK, Shiner RJ, Partridge MR. Is air travel safe for those with lung disease? Eur Respir J. 2007;30(6):1057-1063. doi:10.1183/09031936.00024707.

88. Edvardsen A, Akerø A, Christensen CC, Ryg M, Skjønsberg OH. Air travel and chronic obstructive pulmonary disease: a new algorithm for pre-flight evaluation. Thorax. 2012;67(11):964969. doi:10.1136/thoraxjnl-2012-201855.

89. Edvardsen A, Ryg M, Akerø A, Christensen CC, Skjønsberg $\mathrm{OH}$. COPD and air travel: does hypoxia-altitude simulation testing predict in-flight respiratory symptoms? Eur Respir J. 2013; 42(5):1216-1223. doi:10.1183/09031936.00157112.

90. Mohr LC. Hypoxia during air travel in adults with pulmonary disease. Am J Med Sci. 2008;335(1):71-79. doi:10.1097/ MAJ.0b013e31815f1e35.

91. Akerø A, Christensen CC, Edvardsen A, Skjønsberg OH. Hypoxaemia in chronic obstructive pulmonary disease patients during a commercial flight. Eur Respir J. 2005;25(4):725-730. doi:10.1183/09031936.05.00093104.

92. Seccombe LM, Kelly PT, Wong CK, Rogers PG, Lim S, Peters MJ. Effect of simulated commercial flight on oxygenation in patients with interstitial lung disease and chronic obstructive pulmonary disease. Thorax. 2004;59(11):966-970. doi:10.1136/ thx.2004.022210.

93. Toff WD, Jones CI, Ford I, et al. Effect of hypobaric hypoxia, simulating conditions during long-haul air travel, on coagulation, fibrinolysis, platelet function, and endothelial activation. JAMA. 2006;295(19):2251-2261. doi:10.1001/ jama.295.19.2251.

94. Hughes R, Heuser T, Hill S, et al. Recent air travel and venous thromboembolism resulting in hospital admission. Respirology. 2006;11(1):75-79. doi:10.1111/j.1440-1843.2006.00787.x.

95. Rizkallah J, Man SFP, Sin DD. Prevalence of pulmonary embolism in acute exacerbations of COPD: a systematic review and metaanalysis. Chest. 2009;135(3):786-793. doi:10.1378/ chest.08-1516.

96. White J, Paton JY, Niven R, Pinnock H. Guidelines for the diagnosis and management of asthma: a look at the key differences between BTS/SIGN and NICE. Thorax. 2018;73(3):293-297. doi:10.1136/thoraxjnl-2017-211189.

97. British Thoracic Society. Scottish Intercollegiate Guidelines Network. In: British Guideline on the Management of Asthma: A National Clinical Guideline. SIGN; 2016.

98. McCracken JL, Veeranki SP, Ameredes BT, Calhoun WJ. Diagnosis and management of asthma in adults: a review. JAMA. 2017; 318(3):279-290. doi:10.1001/jama.2017.8372.

99. García-Río F, Calle M, Burgos F, et al. Spirometry. Spanish society of pulmonology and thoracic surgery (SEPAR). Arch Bronconeumol. 2013;49(9):388-401. doi:10.1016/j. arbres.2013.04.001.

100. Berntsen S, Stensrud T, Ingjer F, Vilberg A, Carlsen KH. Asthma in medium altitude--exercise-induced bronchoconstriction in hypobaric environment in subjects with asthma. Allergy. 2005;60(10):1308-1311. doi:10.1111/j.1398-9995.2005.00914.x.

101. Louie D, Paré PD. Physiological changes at altitude in nonasthmatic and asthmatic subjects. Can Respir J. 2004;11(3):197-199. doi:10.1155/2004/734760.

102. Qureshi A, Porter KM. Emergencies in the air. Emerg Med J. 2005; 22(9):658-659. doi:10.1136/emj.2005.024505.

103. Dowdall N. "Is there a doctor on the aircraft?" top 10 inflight medical emergencies. BMJ. 2000;321(7272):1336-1337. 
doi:10.1136/bmj.321.7272.1336.

104. Nicholson TT, Sznajder JI. Fitness to fly in patients with lung disease. Ann Am Thorac Soc. 2014;11(10):1614-1622. doi:10.1513/AnnalsATS.201406-234PS.

105. Ferrer Guillén B, Giácaman MM, Valenzuela Oñate C, Magdaleno Tapial J, Hernández Bel P, Pérez Ferriols A. Pirfenidone-induced photosensitivity confirmed by pathological phototest. Photodiagnosis Photodyn Ther. 2019;25:103-105. doi:10.1016/j.pdpdt.2018.11.015.

106. Hirche TO, Bradley J, d'Alquen D, et al. Travelling with cystic fibrosis: recommendations for patients and care team members. J Cyst Fibros. 2010;9(6):385-399. doi:10.1016/j.jcf.2010.08.013.

107. Miller R, Blanch L, Lenaghan S, Anderson A, Doe S, Bourke SJ. Travelling abroad with cystic fibrosis: assessment of risks and healthcare requirements. Respir Med. 2017;125:92-93. doi:10.1016/j.rmed.2017.01.007.

108. Chetta A, Castagnetti C, Aiello M, et al. Walking capacity and fitness to fly in patients with chronic respiratory disease. Aviat Space Environ Med. 2007;78(8):789-792.

109. Buchdahl RM, Babiker A, Bush A, Cramer D. Predicting hypoxaemia during flights in children with cystic fibrosis. Thorax. 2001;56(11):877-879. doi:10.1136/thorax.56.11.877.

110. Thews O, Fleck B, Kamin WE, Rose DM. Respiratory function and blood gas variables in cystic fibrosis patients during reduced environmental pressure. Eur J Appl Physiol. 2004;92(45):493-497. doi:10.1007/s00421-004-1106-5.

111. Fischer R, Lang SM, Brückner K, et al. Lung function in adults with cystic fibrosis at altitude: impact on air travel. Eur Respir J. 2005; 25(4):718-724. doi:10.1183/09031936.05.10087304.

112. Martin SE, Bradley JM, Buick JB, Bradbury I, Elborn JS. Flight assessment in patients with respiratory disease: hypoxic challenge testing vs. predictive equations. QJM. 2007;100(6):361-367. doi:10.1093/qjmed/hcm033.

113. Edvardsen E, Akerø A, Skjønsberg OH, Skrede B. Pre-flight evaluation of adult patients with cystic fibrosis: a cross-sectional study. BMC Res Notes. 2017;10(1):84. doi:10.1186/s13104-0172386-2.

114. Swisher AK, Hebestreit H, Mejia-Downs A, et al. Exercise and habitual physical activity for people with cystic fibrosis: expert consensus, evidence-based guide for advising patients. Cardiopulm Phys Ther J. 2015;26(4):85-98. doi:10.1097/ cpt.0000000000000016.

115. O'Carroll MR, Kidd TJ, Coulter C, et al. Burkholderia pseudomallei: another emerging pathogen in cystic fibrosis. Thorax. 2003;58(12):1087-1091.doi:10.1136/thorax.58.12.1087.

116. Webb AK. Flying and cystic fibrosis: getting there and back safely. Thorax. 2001;56(11):821-822. doi:10.1136/thorax.56.11.821.

117. Verma A, Dodd ME, Haworth CS, Webb AK. Holidays and cystic fibrosis. J R Soc Med. 2000;93 Suppl 38(Suppl 38):20-26.

118. Kamin WE, Fleck B, Rose D. Intensified physiotherapy improves fitness to fly in cystic fibrosis patients. Eur J Med Res. 2000;5(9):402-404.

119. Burnett JC. Long- and short-haul travel by air: issues for people with diabetes on insulin. J Travel Med. 2006;13(5):255-260. doi:10.1111/j.1708-8305.2006.00057.x.

120. Mullin R, Kruger D, Young CF, Shubrook JH. Navigating travel with diabetes. Cleve Clin J Med. 2018;85(7):537-542. doi:10.3949/ccjm.85a.17105.

121. Trikudanathan S, Hirsch IB. Diabetes management "up in the air": it's time for consensus. Endocr Pract. 2018;24(6):599-601. doi:10.4158/ep-2017-0258.

122. Izadi M, Hosseini MS, Pazham H. Travel guidance for people with diabetes; a narrative review. Int J Travel Med Glob Health. 2015; 3(4):143-147. doi:10.20286/ijtmgh-0304128.

123. Levy-Shraga Y, Hamiel U, Yaron M, Pinhas-Hamiel O. Health risks of young adult travelers with type 1 diabetes. J Travel Med. 2014; 21(6):391-396. doi:10.1111/jtm.12136.

124. American Diabetes Association (ADA). The Path to Understanding Diabetes Starts Here. ADA; 2019.

125. International Association for Medical Assistance to Travellers (IAMAT). Traveller with Health Condition. https://www.iamat. org/travelling-with-diabetes. Accessed on 21 Aug 2019.

126. Diabetes UK. Travel and Diabetes. Diabetes UK; 2019. https:// www.diabetes.org.uk/guide-to-diabetes/life-with-diabetes/ travel. Accessed August 21, 2019.

127. Pavela J, Suresh R, Blue RS, Mathers CH, Belalcazar LM. Management of diabetes during air travel: a systematic literature review of current recommendations and their supporting evidence. Endocr Pract. 2018;24(2):205-219. doi:10.4158/ ep171954.ra.

128. Chełmińska K, Jaremin B. Travelling diabetics. Int Marit Health. 2002;53(1-4):67-76.

129. Pinsker JE, Becker E, Mahnke CB, Ching M, Larson NS, Roy D. Extensive clinical experience: a simple guide to basal insulin adjustments for long-distance travel. J Diabetes Metab Disord. 2013;12(1):59. doi:10.1186/2251-6581-12-59.

130. Nassar AA, Cook CB, Edelman S. Diabetes management during travel. Diabetes Manag. 2012;2(3):205-212. doi:10.2217/ dmt.12.23.

131. Itzstein D. Travelling with diabetes medicines. Australian Pharmacist. 2017;36(10):44-47.

132. Westphal S, Nassar AA, Childs RD, et al. Diabetes selfmanagement in the heat. Pract Diabetol. 2011:21-25.

133. Cook CB, Wellik KE, Fowke M. Geoenvironmental diabetology. J Diabetes Sci Technol. 2011;5(4):834-842. doi:10.1177/193229 681100500402.

134. Nassar AA, Childs RD, Boyle ME, et al. Diabetes in the desert: what do patients know about the heat? J Diabetes Sci Technol. 2010;4(5):1156-1163. doi:10.1177/193229681000400514.

135. Westphal SA, Childs RD, Seifert KM, et al. Managing diabetes in the heat: potential issues and concerns. Endocr Pract. 2010;16(3):506-511. doi:10.4158/ep09344.ra.

136. Hieronymus L, Hepner A. Eating well while traveling. Diabetes Self Manag. 2011;28(3):48-52.

137. Pape J. Lower-carb options. Diabetes Health. 2004;13(6):34.

138. Lumber T, Strainic PA. Have insulin, will travel. Planning ahead will make traveling with insulin smooth sailing. Diabetes Forecast. 2005;58(8):50-54.

139. Ghosh S, Bajaj S, Chatterjee P, et al. Diabetes and travel. Int J Diabetes Dev Ctries. 2018;38(1):4-10. doi:10.1007/s13410-0180605-6.

140. Jawad F, Kalra S. Diabetes and travel. J Pak Med Assoc. 2016;66(10):1347-1348.

141. Casey P. Preparing our patients for travel. Pract Diabetol. 2011;30(4):26-28.

142. Hastings JD. Air Travel for Passengers with Neurological Conditions. Aerospace Medical Association (AsMA); 2014. https://www.asma.org/asma/media/asma/Travel-Publications/ Medical\%20Guidelines/Neurology-Sep-2014.pdf. Accessed August 22, 2019.

143. Alonso-Cánovas A, de Felipe-Mimbrera A, González-Valcárcel J, García-Barragán N, Corral I, Masjuan J. Neurology at the airport. J Neurol Neurosurg Psychiatry. 2011;82(9):981-985. doi:10.1136/jnnp.2011.243709. 
144. Sirven JI, Claypool DW, Sahs KL, et al. Is there a neurologist on this flight? Neurology. 2002;58(12):1739-1744. doi:10.1212/ wnl.58.12.1739.

145. Barros A, Duchateau FX, Huff JS, Verner L, O'Connor RE, Brady WJ. Nonurgent commercial air travel after nonhemorrhagic cerebrovascular accident. Air Med J. 2014;33(3):106-108. doi:10.1016/j.amj.2014.02.003.

146. Naidu Y, Muzerengi S, Tang D, Tluk S, Forbes A, Chaudhuri KR. Travelling related worsening of parkinsonism in Parkinson's disease. Parkinsonism Relat Disord. 2007(13):S186.

147. Gradwell D, Rainford D. Ernsting's Aviation and Space Medicine. $5^{\text {th }}$ ed. CRC Press; 2016.

148. Izadi M, Is'haqi A, Is'haqi MA, Jonaidi Jafari N, Rahamaty F, Banki A. An overview of travel-associated central nervous system infectious diseases: risk assessment, general considerations and future directions. Asian Pac J Trop Biomed. 2014;4(8):589-596. doi:10.12980/apjtb.4.2014apjtb-2014-0065.

149. Boggild A, Brophy J, Charlebois P, et al. Summary of recommendations on malaria issues in special hosts. Can Commun Dis Rep. 2014;40(10):178-191. doi:10.14745/ccdr. v40i10a02.

150. Giovanetti F. Travel medicine interventions and neurological disease. Travel Med Infect Dis. 2007;5(1):7-17. doi:10.1016/j. tmaid.2006.03.002.

151. Fischer PR, Walker E. Myasthenia and malaria medicines. J Travel Med. 2002;9(5):267-268. doi:10.2310/7060.2002.24216.

152. Brunette GW. CDC Yellow Book 2018: Health Information for International Travel. Oxford: Oxford University Press; 2017.

153. Corbett RW, Prout V, Haynes D, Edwards C, Frankel AH. Problems associated with hemodialysis and travel. J Travel Med. 2014; 21(4):255-259. doi:10.1111/jtm.12121.

154. Avery RK, Michaels M. Update on immunizations in solid organ transplant recipients: what clinicians need to know. Am J Transplant. 2008;8(1):9-14. doi:10.1111/j.16006143.2007.02051.x.

155. Scharpé J, Evenepoel P, Maes B, et al. Influenza vaccination is efficacious and safe in renal transplant recipients. Am J Transplant. 2008;8(2):332-337. doi:10.1111/j.16006143.2007.02066.x.

156. Knotek B, Biel L. Peritoneal dialysis travel "tool box". Nephrol Nurs J. 2004;31(5):549-579, 589.

157. Sartorius N, GaebelW, Cleveland HR, etal. WPAguidance on how to combat stigmatization of psychiatry and psychiatrists. World Psychiatry. 2010;9(3):131-144. doi:10.1002/j.2051-5545.2010. tb00296.x.

158. Maher S, Mikic Z, McDonald C, Flaherty GT, Hallahan B. Experiences of international travel in patients with psychotic illness: a case series. Ir J Psychol Med. 2020:1-7. doi:10.1017/ ipm.2019.52.

159. Zhi GYJ, Flaherty GT, Hallahan B. Final journeys: exploring the realities of suicide tourism. J Travel Med. 2019;26(3). doi:10.1093/jtm/taz016.

160. Felkai P, Kurimay T. The most vulnerable travelers: patients with mental disorders. World Psychiatry. 2011;10(3):237. doi:10.1002/j.2051-5545.2011.tb00063.x.

161. Potasman I, Beny A, Seligmann H. Neuropsychiatric problems in 2,500 long-term young travelers to the tropics. J Travel Med. 2000;7(1):5-9. doi:10.2310/7060.2000.00002.

162. Wieshmann UC, Anjoyeb M, Lucas BB. Severe mental illness and airports-the scope of the problem. Psychol Bull. 2001;25(7):261-264. doi:10.1192/pb.25.7.261.

163. Palinkas LA, Suedfeld P. Psychological effects of polar expeditions. Lancet. 2008;371(9607):153-163. doi:10.1016/ s0140-6736(07)61056-3.

164. Spangler R. Psychiatric emergencies. In: In-Flight Medical Emergencies. Cham: Springer; 2018. p. 73-82.

165. Anglin L, Neves P, Giesbrecht N, Kobus-Matthews M. Alcoholrelated air rage: from damage control to primary prevention. J Prim Prev. 2003;23(3):283-297. doi:10.1023/a:1021341707993.

166. Katz G. Jet lag and psychotic disorders. Curr Psychiatry Rep. 2011; 13(3):187-192. doi:10.1007/s11920-011-0192-4.

167. Monti JM, BaHammam AS, Pandi-Perumal SR, et al. Sleep and circadian rhythm dysregulation in schizophrenia. Prog Neuropsychopharmacol Biol Psychiatry. 2013;43:209-216. doi:10.1016/j.pnpbp.2012.12.021.

168. Herxheimer A, Petrie KJ. Melatonin for the prevention and treatment of jet lag. Cochrane Database Syst Rev. 2002(2):CD001520. doi:10.1002/14651858.cd001520.

169. Brzezinski A, Vangel MG, Wurtman RJ, et al. Effects of exogenous melatonin on sleep: a meta-analysis. Sleep Med Rev. 2005;9(1):41-50. doi:10.1016/j.smrv.2004.06.004.

170. Srinivasan V, De Berardis D, Shillcutt SD, Brzezinski A. Role of melatonin in mood disorders and the antidepressant effects of agomelatine. Expert Opin Investig Drugs. 2012;21(10):15031522. doi:10.1517/13543784.2012.711314.

171. Wu CS, Lin CC, Chang CM, et al. Antipsychotic treatment and the occurrence of venous thromboembolism: a 10-year nationwide registry study. J Clin Psychiatry. 2013;74(9):918924. doi:10.4088/JCP.12m08117.

172. Bliss SA, Warnock JK. Psychiatric medications: adverse cutaneous drug reactions. Clin Dermatol. 2013;31(1):101-109. doi:10.1016/j.clindermatol.2011.11.014.

173. Ritchie EC, Block J, Nevin RL. Psychiatric side effects of mefloquine: applications to forensic psychiatry. J Am Acad Psychiatry Law. 2013;41(2):224-235.

174. Wells TS, Smith TC, Smith B, et al. Mefloquine use and hospitalizations among US service members, 2002-2004. Am J Trop Med Hyg. 2006;74(5):744-749. doi:10.4269/ ajtmh.2006.74.744.

175. Meier CR, Wilcock K, Jick SS. The risk of severe depression, psychosis or panic attacks with prophylactic antimalarials. Drug Saf. 2004;27(3):203-213. doi:10.2165/00002018-20042703000005.

176. Felkai P, Kurimay T. Patients with mental problems - the most defenseless travellers. J Travel Med. 2017;24(5). doi:10.1093/ $\mathrm{jtm} / \mathrm{tax} 005$.

177. Schatzberg AF, DeBattista. Manual of Clinical Psychopharmacology. Washington, DC: American Psychiatric Publishing; 2015.

178. Darrat M, Flaherty GT. An exploratory study of medical cover policies offered by the travel health insurance industry. Int J Med Res Health Sci. 2019;8(8):1-8.

179. Han CT, Flaherty G. Profile of travelers with preexisting medical conditions attending a specialist travel medicine clinic in Ireland. J Travel Med. 2015;22(5):312-317. doi:10.1111/ jtm.12221.

180. Gudmundsson A, Stevenson JM, Petrovic M, et al. Challenges and risks for older travellers with multimorbidity: focus on pharmacotherapy. Eur Geriatr Med. 2016;7(5):407-410. doi:10.1016/j.eurger.2016.03.005.

181. Tinetti ME, Fried TR, Boyd CM. Designing health care for the most common chronic condition--multimorbidity. JAMA. 2012; 307(23):2493-2494. doi:10.1001/jama.2012.5265.

182. Bauer KA. Pros and cons of new oral anticoagulants. 
Hematology Am Soc Hematol Educ Program. 2013;2013:464470. doi:10.1182/asheducation-2013.1.464.

183. Garcia D, Libby E, Crowther MA. The new oral anticoagulants. Blood. 2010;115(1):15-20. doi:10.1182/blood-2009-09-241851.

184. Ansell J, Hirsh J, Hylek E, Jacobson A, Crowther M, Palareti G. Pharmacology and management of the vitamin $\mathrm{K}$ antagonists: American College of Chest Physicians evidence-based clinical practice guidelines (8th Edition). Chest. 2008;133(6 Suppl):160S-198S. doi:10.1378/chest.08-0670.

185. Nunnally B, Josseaume J, Duchateau FX, O'Connor RE, Verner L, Brady WJ. Anticoagulation and non-urgent commercial air travel: a review of the literature. Air Med J. 2015;34(5):269-277. doi:10.1016/j.amj.2015.06.006.

186. Tennant SM, Hartland EL, Phumoonna T, et al. Influence of gastric acid on susceptibility to infection with ingested bacterial pathogens. Infect Immun. 2008;76(2):639-645. doi:10.1128/ iai.01138-07.

187. Bavishi C, Dupont HL. Systematic review: the use of proton pump inhibitors and increased susceptibility to enteric infection. Aliment Pharmacol Ther. 2011;34(11-12):1269-1281. doi:10.1111/j.1365-2036.2011.04874.x.

188. Tudball J, Ryan K, Manias E, Smith L. Travelling with multiple medicines: a source of medication error and nonadherent 'forgetting'. Res Social Adm Pharm. 2014;10(5):e57. doi:10.1016/j.sapharm.2014.07.144.

189. Zwar N. Travelling with medicines in 2018. Aust Prescr. 2018; 41(4):102-104. doi:10.18773/austprescr.2018.034.

190. Wu Z, McGoogan JM. Characteristics of and important lessons from the coronavirus disease 2019 (COVID-19) outbreak in China: summary of a report of 72314 cases from the Chinese Center for Disease Control and Prevention. JAMA. 2020;323(13):1239-1242. doi:10.1001/jama.2020.2648.

191. Yang J, Zheng Y, Gou X, et al. Prevalence of comorbidities and its effects in patients infected with SARS-CoV-2: a systematic review and meta-analysis. Int J Infect Dis. 2020;94:91-95. doi:10.1016/j.ijid.2020.03.017. 